\title{
Uji Toksisitas Ekstrak Batang Pinang Yaki (Areca vestiaria) pada Artemia salina Leach.
}

\author{
Windy AstutiTampungan ${ }^{1)}$, Herny I.E. Simbala ${ }^{2)^{*}}$, Edwin de Queljoe ${ }^{2)}$, Stenly Wullur ${ }^{3)}$ \\ 1) Alumni Jurusan Biologi Fakultas MIPA Universitas Sam Ratulangi Manado \\ 2) Jurusan Biologi Fakultas MIPA Universitas Sam Ratulangi Manado \\ ${ }^{3)}$ Fakultas Perikanan dan Kelautan Universitas Sam Ratulangi Manado \\ E-mail korespondensi: hsimbala@yahoo.co.id
}

Diterima 4 April 2011, diterima untuk dipublikasikan 4 Juli 2011

\begin{abstract}
Abstrak
Efek toksisitas pinang yaki (Areca vestaria) sebagai tumbuhan obat potensial perlu diuji untuk mengetahui ambang batas penggunaannya. Penelitian ini bertujuan untuk menguji tingkat toksisitas ekstrak batang pinang yaki terhadap larva Artemia salina Leach. dengan metode Brine Shrimp Lethality Test. Ekstrak diencerkan dengan konsentrasi 200, 400, 600 dan 800 ppm masing-masing untuk supernatan rendaman pertama (larutan A), supernatan rendaman ke dua (larutan B) dan supernatan rendaman ke tiga (larutan C). Hasil penelitian menunjukkan bahwa ekstrak batang pinang yaki mempunyai efek toksisitas dengan nilai $L C_{50}$ sebesar 398,28 ppm untuk larutan A, 390,84 ppm untuk larutan B dan 438,53 ppm untuk larutan $C$.

Kata kunci: batang Areca vestaria, $L C_{50}$, uji toksisitas
\end{abstract}

\section{Abstract}

Toxicity effect of pinang yaki (Areca vestiaria) as potential medicinal plant should be evaluated to know its application threshold. This research aimed to evaluate the toxicity level of pinang yaki trunk extract on larve of Artemia salina Leach. using the method of Brine Shrimp Lethality Test. Extract was diluted to concentration of 200, 400, 600 and 800 ppm each for solution $A$ (first soaking supernatant), solution $B$ (second soaking supernatant)and solution $C$ (third soaking supernatant). The result of this research showed that extract of pinang yaki trunk had a toxic characteristic, with $L C_{50}$ value was 398,28, 390,84, and 438,53 ppm respectively for solution $A, B$ and $C$.

Keywords: $L C_{50}$, toxicity test, trunk of Areca vestaria

\section{PENDAHULUAN}

Penggunaan tumbuhan sebagai obat telah lama kita ketahui, bahkan menurut data WHO pada tahun 1993, 80 $\%$ penduduk dunia masih mengandalkan pengobatan tradisonal. Tetapi penggunaan tumbuhan obat ini biasanya hanya berdasarkan pengalaman empiris dan belum teruji secara ilmiah. Oleh sebab itu perlu diuji untuk mengetahui efek farmakologis dan efek toksik tumbuhan tersebut. Pinang yaki (Areca vestiaria) merupakan pinang endemik Sulawesi Utara. Tumbuhan ini digunakan oleh masyarakat Bolaang Mongondow sebagai tumbuhan obat. Efek farmakologis tumbuhan ini sebagai antikanker, antitumor, antioksidan, antibakteri dan antifertilitas (Simbala 2007) disebabkan oleh kandungan tanin, flavonoid, steroid, hidrokuinon dan triterpenoid (Lenny 2006).

Uji toksisitas merupakan uji pendahuluan yang dilakukan untuk mengetahui efek toksik dan ambang batas penggunaan suatu tumbuhan sebagai obat. Uji toksisitas dapat dilakukan dengan menggunakan metode Brine Shrimp Lethality Test terhadap larva Artemia salina Leach. (Meyer et al. 1982). A. salina Leach. merupakan udang-udangan primitif yang termasuk dalam Filum Arthropoda. 
Udang ini hidup sebagai plankton di perairan dengan kadar garam 5-150 ppm, dengan suhu sekitar $25-30{ }^{\circ} \mathrm{C}$, kadar oksigen 2-7 ppm dan $\mathrm{pH}$ 7,3-8,4.

\section{METODE PENELITIAN}

Penelitian yang dilakukan pada bulan Maret-April 2010 ini menggunakan metode eksperimental dengan perlakuan konsentrasi ekstrak batang pinang yaki dalam 3 kali ulangan.

\section{Ekstraksi Batang Pinang Yaki}

Ekstraksi dilakukan di Laboratorium Advanced Fakultas MIPA UNSRAT. Batang pinang yaki yang sudah dibersikan, dipotong kecil-kecil, dikeringkan lalu diblender sampai menjadi serbuk. Lalu serbuk direndam dengan pelarut etanol 96 \% selama 24 jam (Harbone 1987). Rendaman tersebut disaring dan diperoleh supernatant untuk larutan A. Residunya direndam kembali dengan cara yang sama untuk mendaptkan larutan B, dan residu larutan B direndam kembali untuk memperoleh larutan C. Ketiga supernatant tersebut dievaporasi untuk mendapatkan ekstrak murni batang pinang yaki. Selanjutnya ketiga macam ekstrak tersebut diencerkan masing-masing 200, 400, 600 dan 800 ppm.

\section{Persiapan Hewan Uji} Hewan uji yang digunakan dalam penelitian ini adalah larva $A$. salina Leach. yang sudah ditetaskan terlebih dahulu. Proses penetasan dilakukan di dalam toples yang sudah berisi air laut 34 ppt, dan dilengkapi dengan 2 buah aerator pada suhu ruangan $30^{\circ} \mathrm{C}$ sampai larva berumur 48 hari (Nurhayati et al. 2006).

\section{Uji Toksisitas}

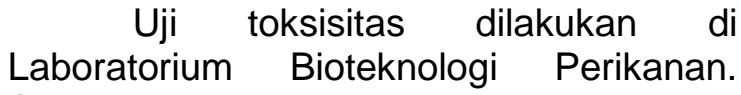
Sepuluh larva $A$. salina Leach. yang telah menetas selama 48 jam dimasukkan ke dalam botol berisi $5 \mathrm{ml}$ air laut yang sudah diberi $5 \mathrm{ml}$ larutan sampel dengan konsentrasi 200, 400, 600, dan 800 ppm sebanyak 3 ulangan. Sepuluh larva $A$. salina Leach. dalam $10 \mathrm{ml}$ air laut steril dengan kadar salinitas 34 ppt digunakan sebagai kontrol. Penghitungan jumlah larva yang mati, dilakukan sebanyak 5 kali, yaitu pada jam ke-3, 6, 9, 12 dan 24 dengan bantuan mikroskop (Widyastuti 2008).

\section{Analisis Data}

Data dianalisis untuk memperoleh persentase mortalitas kumulatif dengan rumus

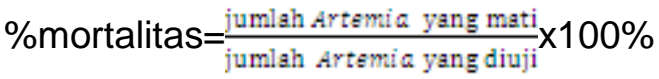

Selanjutnya angka kematian dicari dengan menggunakan grafik persamaan regresi linier dan mensubtitusikan dengan angka probit.

\section{HASIL DAN PEMBAHASAN}

\section{Persentase Mortalitas Hewan Uji}

Ekstrak batang pinang yaki dengan berbagai konsentrasi berpengaruh signifikan terhadap mortalitas larva $A$. salina Leach. (Gambar 1). 

10 JURNAL BIOSLOGOS, AGUSTUS 2011, VOL. 1 NOMOR 1

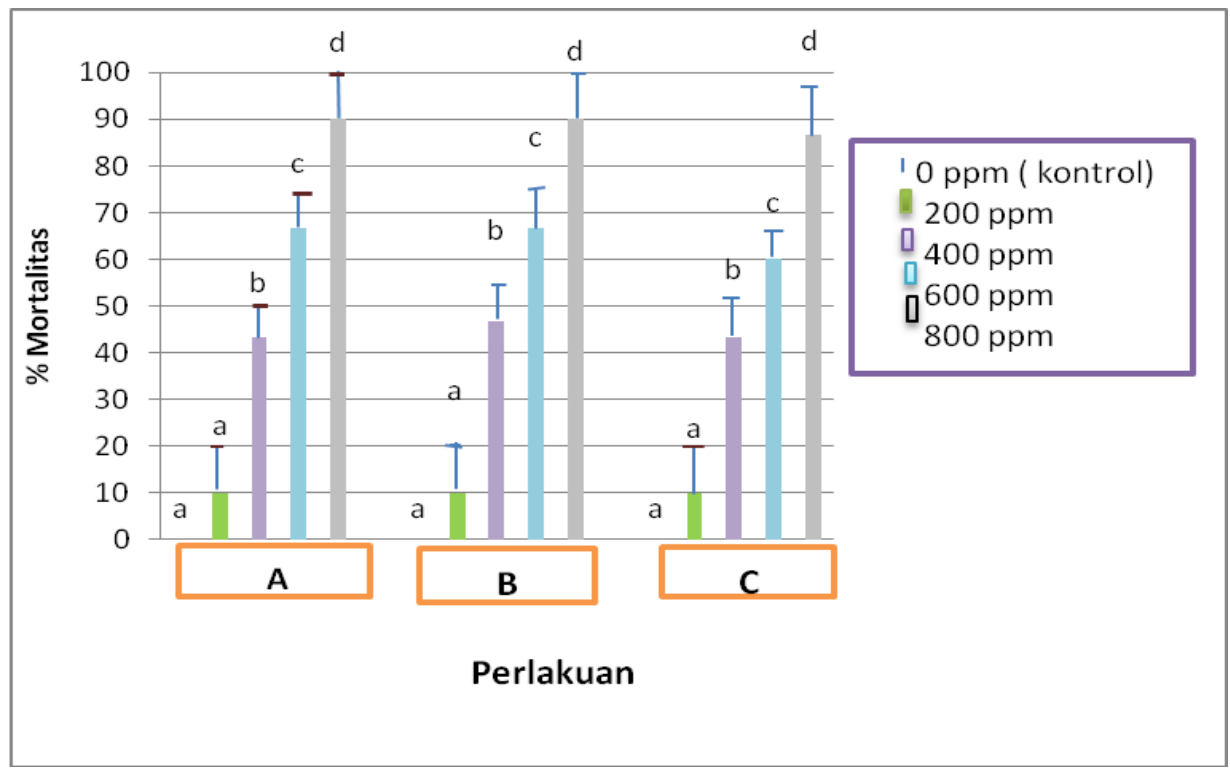

Gambar 1. Pengaruh larutan A, B dan C (dengan konsentrasi 0-800 ppm) terhadap mortalitas A. salina Leach. $\mathrm{a}<\mathrm{b}<\mathrm{c}<\mathrm{d}$ (Tukey Kramer Post Hoc Test $p>0,05$ )

Hasil Anava satu arah menunjukkan bahwa setiap larutan dengan masingmasing konsentrasi berpengaruh signifikan $(p \leq 0,001)$ terhadap mortalitas $A$. salina Leach.. Hasil uji Tukey Kramer Post Hoc Test menunjukkan bahwa pengaruh larutan A, B dan C untuk konsentrasi 200 ppm terhadap mortalitas $A$. salina Leach. tidak berbeda signifikan jika dibandingkan dengan kontrol $(0 \mathrm{ppm})$, tetapi berbeda signifikan jika dibandingkan dengan konsentrasi 400, 600 dan $800 \mathrm{ppm}(p>$ $0,05)$. Mortalitas $A$. salina Leach. setelah 24 jam dalam ekstrak batang pinang yaki untuk setiap larutan A, B dan C dapat dilihat pada Gambar 2, 3 dan 4.

\section{Larutan $A$}

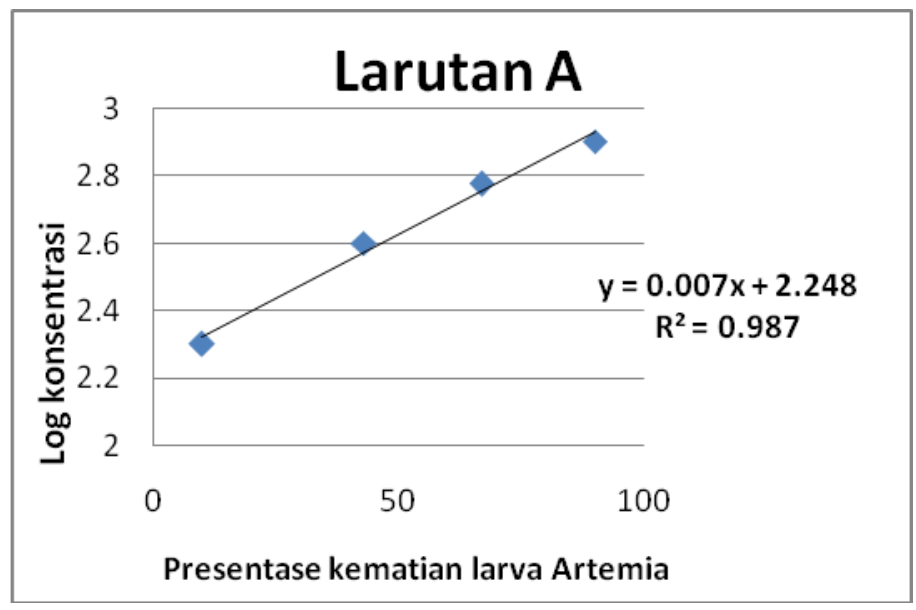

Gambar 2. Grafik hubungan persentase kematian A.salina Leach. dan log konsentrasi ekstrak batang pinang yaki larutan $\mathrm{A}$ 


\section{Larutan B}

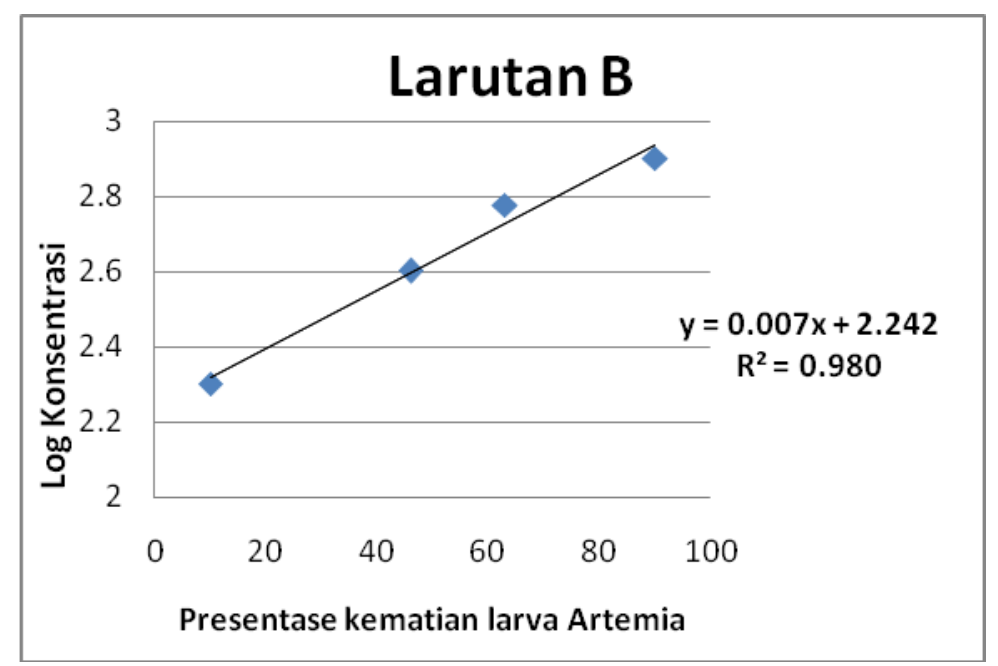

Gambar 3. Grafik hubungan persentase kematian A. salina Leach. dan log konsentrasi ekstrak batang pinang yaki larutan $B$

\section{Larutan C}

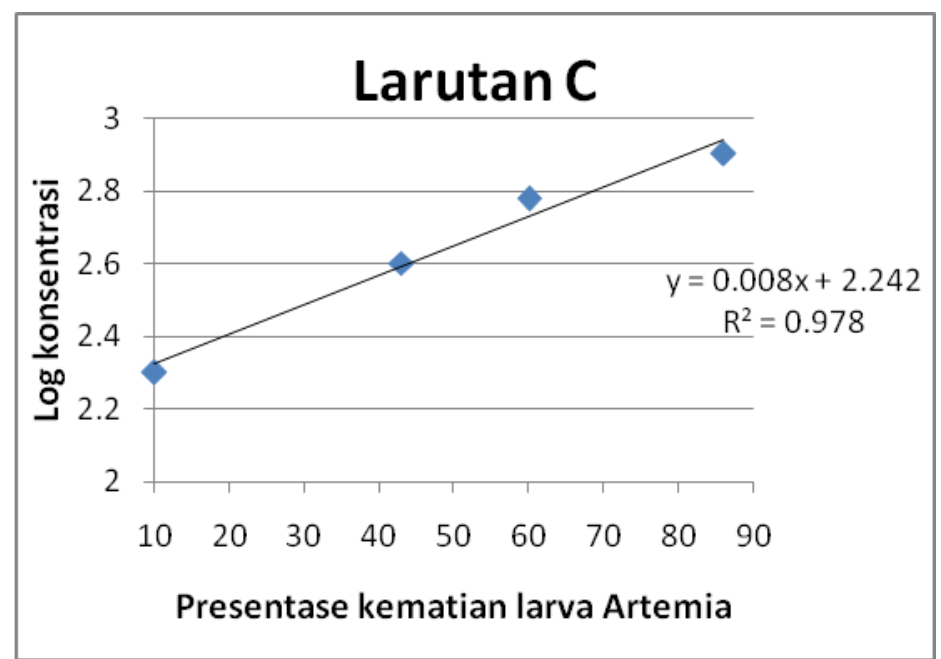

Gambar 4. Grafik hubungan persentase kematian A. salina Leach. dan log konsentrasi ekstrak batang pinang yaki $(A$. vestiaria) larutan $\mathrm{C}$

Variasi cara perendaman ekstrak pinang yaki (larutan A, B dan C) tidak berpengaruh secara signifikan terhadap mortalitas larva $A$. salina Leach., karena nilai $L_{50}$ ketiga larutan tidak berbeda nyata. Hal ini dapat disebabkan karena rendaman untuk larutan A tidak diaduk dalam proses penyaringan, sehingga tidak homogen dan senyawa terlarut tertinggal di dasar wadah. Persamaan regresi linier untuk larutan A (Gambar 2), larutan B (Gambar 3), dan larutan C (Gambar 4) digunakan untuk menenetukan nilai $\mathrm{LC}_{50}$ dengan subtitusi angka 50\% kematian pada $x$, sehingga didapatkan nilai y untuk larutan A sebesar 2,598. Selanjutnya nilai tersebut diantilog dan diperoleh nilai 398,28 . Dengan cara yang sama akan diperoleh nilai y sebesar 2,592 dan nilai antilog sebesar 390,84 untuk larutan B. Nilai y dan nilai antilog untuk larutan C masing-masing adalah 2,642 dan 438,53. Hal ini berarti mortalitas $A$. salina Leach. sebesar $50 \%$ terjadi saat konsentrasi 
senyawa larutan $A, B$ dan $C$ mencapai $398,28,390,84$ dan 438,53 ppm. Nilai LC $_{50}$ ekstrak senyawa sebesar 50-500 digolongkan dalam kriteria cukup toksik (Lomis 1978 dalam Jenova 2009).

\section{KESIMPULAN}

1. Ekstrak batang pinang yaki dengan konsentrasi 400-800 ppm berpengaruh signifikan terhadap mortalitas larva $A$. salina Leach.

2. Nilai LC $_{50}$ adalah 398,$28 ; 390,84$; 438,53 ppm masing-masing untuk larutan $\mathrm{A}, \mathrm{B}$ dan $\mathrm{C}$.

3. Variasi cara perendaman ekstrak pinang yaki (larutan A, B dan C) tidak berpengaruh secara signifikan terhadap mortalitas larva $A$. salina Leach..

\section{DAFTAR PUSTAKA}

Harbone JB (1987) Metode fitokimia. Edisi ke-dua. ITB, Bandung

Jenova $R$ (2009) Uji toksisitas akut yang diukur dengan penentuan $\mathrm{LD}_{50}$ ekstrak herba putri malu (Mimosa pudica) terhadap mencit BALB/C. Skripsi. Univesitas Diponegoro. Semarang

Lenny S (2006) Senyawa terpenoida dan steroida. Departemen Kimia Fakultas Matematika dan IImu Pengetahuan Alam. Universitas Sumatera Utara. Medan

Meyer BN, Ferrigri NR, Putnam JE, Jacobsen LB (1982) Brine shrimp: a convenient general bioassay for active plant constituent. Plant Medica : 31-34

Nurhayati N, Abdulgani R, Febrianto (2006) Uji toksisitas ekstrak Alvaresii terhadap Artemia salina Leach. sebagai studi pendahuluan potensi anti kanker. Program Studi Biologi FMIPA Institut Teknologi Sepuluh November. Surabaya

Simbala H (2007) Keanekaragaman floristic dan pemanfaatannya sebagai tumbuhan obat di kawasan konservasi II Taman Nasional Bogani Nani Wartabone (Kabupaten Bolaang Mongondow Sulawesi Utara. Sekolah Pascasarjana Institut Pertanian Bogor. Bogor

Widyastuti S (2008) Uji toksistas ekstrak daun iprih (Ficus glabella Blume) terhadap Artemia salina Leach. dan profil kromatografi lapis tipis. Skripsi Fakultas Farmasi Universitas Muhamadiyah Surakarta. Surakarta 